\title{
Research of Tribological Features of Steel Surface by Creating Mineral Coatings
}

\author{
Skazochkin Aleksandr V., ${ }^{1, *}$, Bondarenko Gennady G. ${ }^{2}$ and Kislov Stanislav V. ${ }^{3}$ \\ ${ }^{1}$ Kaluga branch of the Russian Presidential Academy of National Economy and Public Administration, Kaluga, Russia \\ *Corresponding author, Okruzhnaya St., 4, building 3, Kaluga, Russia, 248030, e-mail: avskaz@rambler.ru \\ ${ }^{2}$ National Research University Higher School of Economics, Moscow, Russia \\ ${ }^{3}$ Scientific and Production Center "Mico-Tech" Limited Liability Company, Kaluga, Russia
}

Received 30 August 2018; Accepted 3 December 2018

\begin{abstract}
The work investigates some tribological parameters of the surfaces of friction pairs made of steel, with mineral layers. A comparative study of the friction coefficient of $18 \mathrm{CrNiMo} 7-6$ steel specimens with and without a mineral coating is performed. The lowest friction coefficient value was achieved for samples with mineral coating, without HFC hard surfacing before creating a mineral layer, and it was approximately $15 \%$ lower in comparison with the samples with HFC hard surfacing, but without mineral coating. The friction coefficient in the temperature range of $30 \ldots 140{ }^{0} \mathrm{C}$, with constant displacement speed of samples with mineral coatings is practically unchanged for every sample type, the variation range does not exceed 0.02 , as contrasted with the friction coefficient of the samples with hard surfacing, but without mineral coating. The value of the coefficient of volumetric wear of an aluminum oxide toroid during rotation with disks with some types of mineral coatings was at the level of detection limit (less than $1.2 \times 10-9 \mathrm{~mm}^{3} / \mathrm{Nm}$ ), which is significantly less than the coefficient of volume wear of a toroid during rotation with disks without coating (4-7)x10-8 $\mathrm{mm}^{3} / \mathrm{Nm}$.
\end{abstract}

Keywords: metal surface, mineral coating, friction coefficients, wear resistance, volumetric wear coefficient

\section{Introduction}

When metal parts are heated due to friction or exposure to environment, it leads to alteration of some tribological parameters, including, primarily, friction coefficient. The alteration of these parameters may lead to stimulation of destructive processes on the surface of the metal part and in its body which influences its wear resistance and life span [1].

Operational heating and subsequent acceleration of wear process, e.g. friction or roller bearing, speed reducers, worm gears and other parts are typical situations arising during operation of various assemblies and devices [1-2]. That is why stabilization of friction coefficient related to heating of friction surfaces of metal parts is an important and relevant scientific and technical problem.

Intense friction in aggressive environment, e.g. abrasive, sea water, weak acid solutions, hydrogen sulphide, determines the properties of the coatings used for a large group of metal parts. Simply increasing the hardness of the surfaces of rubbing parts to work under such conditions, for example, by creating coatings, does not solve the problem of general wear. The existence of an oxide film on the surface of the metal, which is often the cause of corrosion resistance, creates problems for the creation of reliable wear-resistant coatings using some traditional methods. As practice demonstrated, the creation of coatings and protective films by galvanic methods, chemical-thermal treatment methods,

*E-mail address: avskaz@rambler.rv

ISSN: $1791-2377$ @ 2018 Eastern Macedonia and Thrace Institute of Technology. All rights reserved. doi:10.25103/jestr.116.17 gas-flame spraying, even using extravagant techniques, special modes and composite materials does not meet the necessary operational requirements due to low adhesion, appearance of defects, low chemical resistance [3-4]. We need special ways to change the surface properties of the metal, significantly reducing or even eliminating the problems of adhesion, appearance of defects, reducing scoring when working with lubrication and without lubrication. In general, such results can be obtained using various techniques related to methods of surface modification: laser surface heating, nitriding, carbonization, thermal oxidation and other methods $[2,5]$. However, many of these methods are inefficient both from the point of view of technical parameters and economically, because they are accompanied by continued high-temperature heating, limitation of mass-size dimensions and fragility of the layers obtained. High temperatures can lead to a change in the structure of the metal, a decrease in strength properties, distortions and low yield of usable product [1-2, 4-6]. Therefore, for industrial purposes it is important to develop other methods for modifying metal surface with minimal or low thermal impact, in particular, ion implantation methods, electrospark doping, microarch doping and mineral coating technology [1-2].

The methods using low-temperature operations when creating a modified layer include the so-called technology of mineral coatings [7-8]. The essence of the technology of mineral coatings is to create a modified surface layer 5-30 microns thick due to its plastic deformation using ultrasound and mechanical action along with the diffusion of ultrathin mineral particles into the metal casing, as well as technological know-how technologies [7-8]. 
Skazochkin Aleksandr V., Bondarenko Gennady G. and Kislov Stanislav V./

Journal of Engineering Science and Technology Review 11 (6) (2018) 138 - 143

Determining how a metal part's friction coefficient depends on temperature will sometimes facilitate in predicting life span of parts and assemblies, and serve as a reference experiment for predicting properties of various parts with mineral coatings in other instances.

The purpose of this study is to determine the following tribological parameters of the surfaces of friction pairs made of steel with mineral layers created using the technology [78]:

1. Friction coefficient depending on temperature in ambient conditions;

2. Friction coefficient and volumetric wear coefficient when sliding under conditions of "lubrication" by distilled water or sea water.

\section{Material and Methods}

The essence of friction sliding surface tests in liquids and lubricants is that the sample surface interacts for a specified time at a fixed static load with a steel metal surface according to the "block-roller", "roller-roller", "bushing" pattern -shaft". During the test, the coefficient of friction and wear resistance are determined. Depreciation - the result of wear, defined in established units. The amount of material removed from the friction surface (wear) is measured in units of length (for example, the worn-out layer thickness), volume or mass, and in these cases the wear is called linear, volume or mass, respectively. The use of the type of units determines the type of wear part or device. There are many ways to analyze wear products. Mass measurement is traditional and the simplest - before and after the end of each test cycle the sample under study is weighed and the weight wear of the surface layer is determined. In our experiments, a volume change was calculated from the results of mass measurements. In our experiments, the wear was determined according to the "plug-shaft" scheme: a volume change was calculated from the mass measurement results and normalized to the amount of torque. This friction scheme allows one to study friction in liquid media, as well as in films formed on rubbing surfaces as a result of interaction between the liquid and the material under study. Wear characterizes metal loss during friction parts operation and determines the durability of the friction unit.

Studies of the coefficient of friction and wear resistance were carried out on cylindrical metal samples made in the form of rings of structural steel 18CrNiMo7-6 (first experiment) and or disks of steel $\mathrm{X} 12 \mathrm{Cr} 13$ (second experiment) with a diameter of $35 \mathrm{~mm}$ and a width of 12 $\mathrm{mm}$ created by turning rods on the outer the surfaces of which were created mineral coatings of several types. Figure 1 shows photographs of the appearance of the sample in the first experiment.

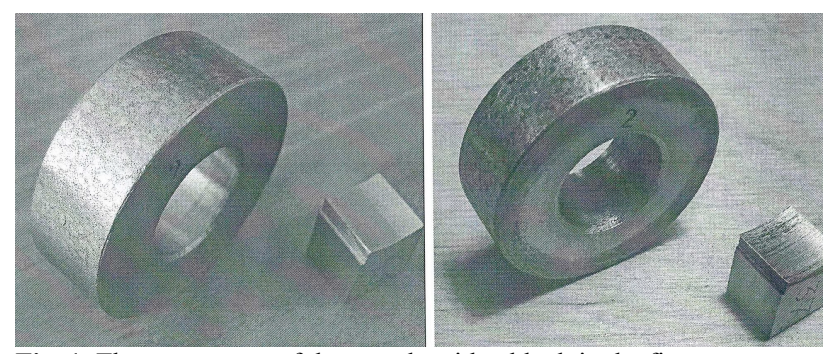

Fig. 1. The appearance of the sample with a block in the first experiment

a) before testing, b) after testing
Before testing, the contact surface of the specimens was ground in order to achieve full adherence of the specimens to the surface of the steel pad under the test conditions. The counter surface of the steel pad was made of steel 45 (the first experiment) and a toroid of aluminum oxide (the second experiment).

In the process of testing using a strain gauge device, the friction force was recorded, from which the friction coefficient was calculated. To determine the weight wear, the sample was weighed before and after each test cycle. According to the results of measuring the weight loss of the samples, the change in the weight of the sample during the test was determined as the difference between the initial and final weight of the sample in each test cycle (mg); according to the results of mass measurements, the change in volume was calculated as the main indicator of wear in the specific device for which the experiment was conducted.

The study of samples were performed on the following equipment:

- SMT-2 friction machine, being a modification of the Amsler friction machine (a schematic diagram is shown in different works, for example $[9,10])$, is intended for materials testing for friction and wear during rolling, sliding and sliding rolling. The friction machine is equipped with devices for calibrating its power systems, temperature measurements in the range of $20 \ldots$ $150^{\circ} \mathrm{C}$, as well as for testing elements of model tribosystems in a liquid medium;

- Electronic scales HTP-120CT with a Tuning Fork sensor, weighing range from $0.01 \mathrm{~g}$ to $120 \mathrm{~g}$ with a resolution of not more than $0.0001 \mathrm{~g}$, the calibration division value is not less than $0.001 \mathrm{~g}$ and accuracy class according to GOST 241042001 (State standard of the Russian Federation) special (I).

In the course of the first experiment, samples made of 18CrNiMo7-6 structural steel received mineral coatings according to the technology [7-8] with various surface roughness $\mathrm{Ra}$ (average roughness).

Below are the results of tests performed with four series of samples (two samples from each series were tested).

- R06 series samples, without mineral coating, were exposed to hard surfacing by highfrequency current (HFC);

- R10 series samples with mineral coating, without HFC hard surfacing before creating a mineral layer;

- G1 series samples (G13 and G14) with mineral coating, without HFC hard surfacing before creating a mineral layer;

- G2 series samples (G15 and G16) with mineral coating, were exposed to hard surfacing by HFC before creating mineral layers;

The dependence of the friction coefficient was investigated with the above mentioned samples within temperature range of $30 \ldots 140{ }^{0} \mathrm{C}$. The linear speed of sample displacement varied from 4 to $74 \mathrm{~mm} / \mathrm{s}$, contact pressure was 550...600 MPa, for lubrication Mobil SHC 639 was used. The choice of this type of oil was based on its application in lubricating gear transmissions and bearings under extreme low and high temperatures or intense loads. 
The oil is typically used in roller bearings, various mixers and roll-neck bearings exposed to high temperature conditions.

In the course of the second experiment wearing of samples with mineral layers and without special treatment was investigated, with disks sliding on a toroid lubricated with Mobil SHC 639 oil. The investigation of sliding in the mode of mixed/boundary lubrication was carried out in distilled water and in synthetic sea water prepared in accordance with DIN 50905 [13].

In this experiment modified mineral layers were created on the surface of metal samples shaped as disks made of $\mathrm{X} 12 \mathrm{Cr} 13$ steel rods by lathing, in accordance with the technology [7-8]. The thickness of the created mineral layers varied from 5 to 20 microns, which had no impact on the results of the experiments. Disks made of $\mathrm{X} 12 \mathrm{Cr} 13$ steel with mineral coating and without mineral coating rotated along toroids made of aluminium oxide (water temperature $\mathrm{T}=23{ }^{0} \mathrm{C}$; vertical load $\mathrm{F}_{\mathrm{N}}=22 \mathrm{~N}$; linear displacement speed $\mathrm{v}=0.1 \mathrm{~m} / \mathrm{s}$; total distance of displacement $\mathrm{s}=2 \mathrm{~km}$ ). In the experiment, the degree of wear of the disks and the toroid was determined according to the "sleeve-shaft" scheme: a volume change was calculated from the results of the mass measurements and normalized by the torque value [11-12].

Synthetic oil based on polybutyleneglycol (GLYMOT PBG B20) and Mobil SHC 639 oil were used in the experiments. The experiments on sliding with lubrication by Mobil SHC oil were performed under contact pressure of $100 \mathrm{MPa}$.

\section{Results and Discussion}

Using the capabilities of the technology of creating mineral coatings, mineral layers of various degrees of roughness were deliberately created on the surface of steel samples in series R10 and G. 3D roughness profiles of various samples are shown in figure 1 (the method for measuring roughness profile by means of 3D optical systems is given a detailed description, e.g. in this work [14]). In Figure 2: a, b samples with mineral coatings without HFC hard surfacing before creating a mineral layers; $\mathrm{c}, \mathrm{d}$ - samples with mineral coatings were exposed to hard surfacing by HFC before creating mineral layers; e, f - samples with mineral coatings without HFC hard surfacing before creating a mineral layers.

Roughness profiles show changes in $\mathrm{Ra}$ (average roughness) by almost an order for various samples ranging from 0.47 to 3.3 microns. In Figure 2 various values of roughness (the scale on the right from each sample's profile) correspond to shades of gray and white which makes it easier to grasp the whole picture.

Figure 3 shows graphs demonstrating dependence of sliding friction coefficient on the speed of sliding for several samples without mineral coating and with mineral coating. In every instance, the friction coefficient is reduced when the sliding speed is increased, which is typical for a mixed lubrication mode. The lowest coefficient was recorded on samples of the G1 series (Figure 3 shows sample G13) with a mineral coating, without HFC hard surfacing before creating the mineral layer. For comparison, Figure 3 shows a sample of the G2 (G15) series with a mineral coating, with HFC hard surfacing before the creation of a mineral layer. The friction coefficient of samples of the G1 series was approximately $15 \%$ lower in comparison with the samples of R06 series (R06-1 in the figure), with HFC hard surfacing, without mineral coating.

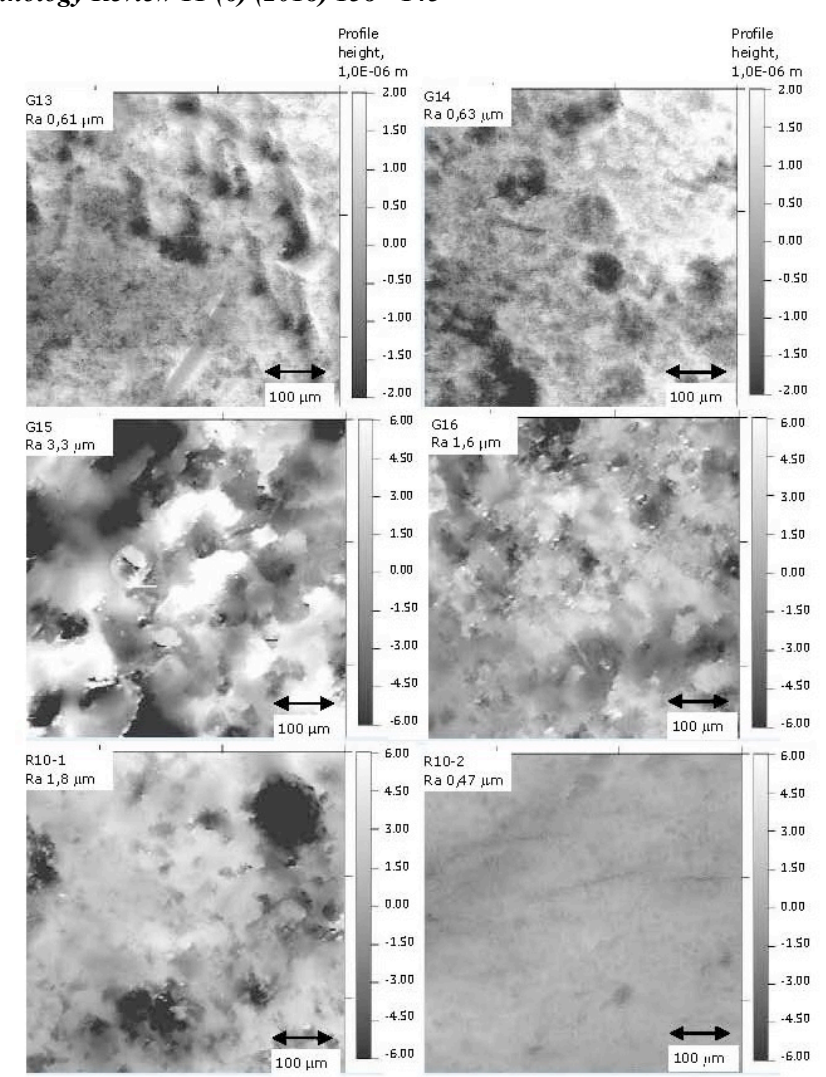

Fig. 2. 3D roughness profiles of various samples (R10, G1, G2 series ) in the first experiment.

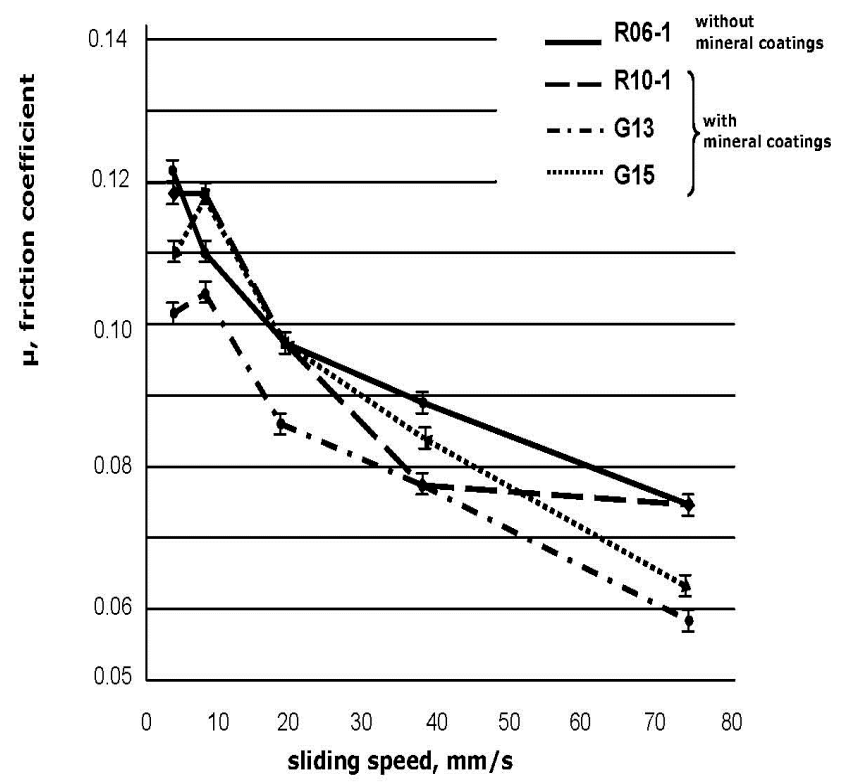

Fig. 3. The dependence of sliding friction coefficient of the samples on sliding speed

Surface treatment of the metal according to the technology of mineral coatings leads to the enrichment of the surface and surface layers with chemically active substances [7], which reduce the seizure and scuffing during friction [15]. In our opinion, the probable cause of a decrease in the friction coefficient of samples of the G1 (G13) series is a sharp decrease in the adhesion of surfaces with mineral particles [15].

Figure 4 shows the measurement results of friction coefficient for all series of the samples (R and $G$ ) depending on temperature. In these experiments the temperature 
Skazochkin Aleksandr V., Bondarenko Gennady G. and Kislov Stanislav V./

Journal of Engineering Science and Technology Review 11 (6) (2018) 138 - 143

increased step by step from $30{ }^{\circ} \mathrm{C}$ to $140{ }^{\circ} \mathrm{C}$, with constant sample displacement speed of $37 \mathrm{~mm} / \mathrm{s}$. In Figure 4: a sample without mineral coating were exposed to hard surfacing by high-frequency current (HFC); b, c - samples with mineral coatings, without HFC hard surfacing before creating a mineral layer; $\mathrm{d}$ - sample with mineral coating, were exposed to hard surfacing by HFC before creating mineral layer.
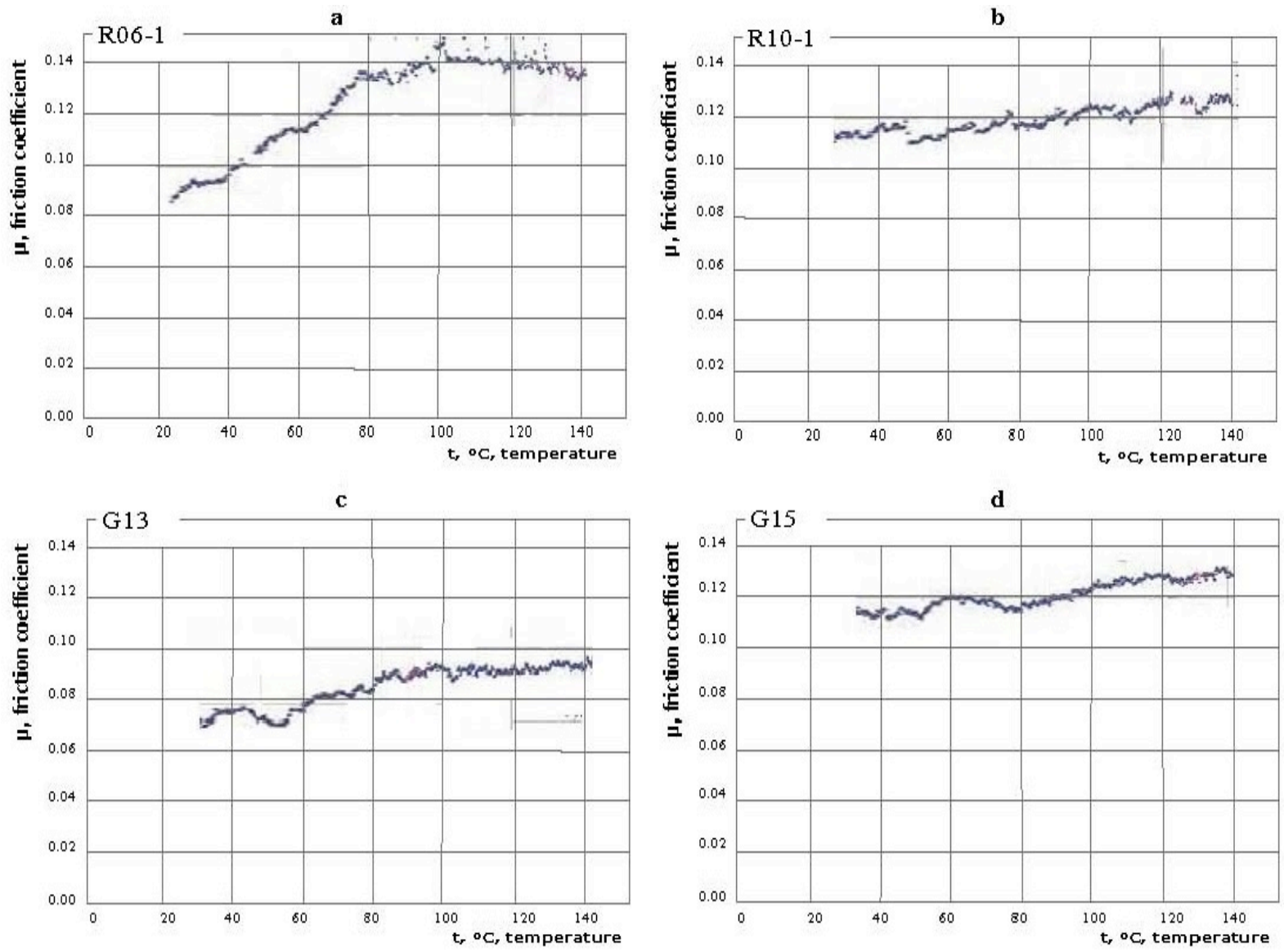

Fig. 4. Diagrams showing the dependence of the friction coefficient of the samples on the temperature.

The observed increase in the friction coefficient of the samples of R06 series (R06-1 in the figure), without mineral coating, with standard HFC hard surfacing, was quite anticipated and related to the change in lube viscosity and/or destruction of the oxidation film on the surface due to friction.

For practical applications, it is rather interesting that for all the samples with mineral coating, treated with hard surfacing before layer formation or not, the friction coefficient in the indicated temperature range remains practically unchanged. The variation range of the friction coefficient in the stated temperature range does not exceed 0.02. Traditionally, the stabilization of the friction coefficient is associated with the state of oxide films on the metal surface. It is possible that in the case of the creation of mineral layers, the stable behavior of the friction coefficient with increasing temperature occurs for the same reason. Here, the role of the film is resistant to temperature changes, a layer modified with minerals.

The generalised results of the second experiment are shown in Figure 5. In this figure specimens (No. 1-12) of $\mathrm{X} 12 \mathrm{Cr} 13$ steel with mineral coating. The right coordinate axis bears values of the friction coefficient for all disks in the experiment, measured after the end of rotation (in sample 1 the coefficient of friction was not measured). Figure 5 shows that the value of the coefficient of volumetric wear of an aluminum oxide toroid during rotation with discs with certain types of mineral coatings (Nos. 2, 4, 9, 10) is less than $1,2 \times 10^{-9} \mathrm{~mm}^{3} / \mathrm{Nm}$, which is significantly less than volumetric wear rate when rotating with uncoated discs (47) $\times 10^{-8} \mathrm{~mm}^{3} / \mathrm{Nm}$. That is, the degree of wear of the alumina toroid conjugated to disks made of $\mathrm{X} 12 \mathrm{Cr} 13$ steel with certain types of mineral coatings during rotation in water was at the level of the detection limit and therefore cannot be accurately quantified in this experiment. It is necessary to repeat the experiment using certain types of mineral coatings, increasing the total length of the displacement and the value of the vertical load.

The technology of mineral coatings, using electrospark alloying, pressing (application of pressure) and ultrasonic treatment in aggregate creates the effect of bulk compression of the base metal and mineral in the zone of plastic deformation, and, as a consequence, hardening of the surface layer. In particular, pressing causes an increase in the density of defects in the surface layers, compressive stresses are created that retard the development of surface cracks [7]. In the present case, the resulting and existing surface defects are filled with particles of minerals. As a result, such a "cold" treatment creates a thin layer containing mineral particles, concentrating in the pre-created microcavities [7]. Filling of microcracks with ultradispersed particles and possible changes that occur with defects may have a decisive influence on the development of defects in the surface hardened layer and affect the sharp increase in wear resistance of the material during work of the parts. This 
Skazochkin Aleksandr V., Bondarenko Gennady G. and Kislov Stanislav V./

Journal of Engineering Science and Technology Review 11 (6) (2018) 138 - 143

assumption requires further studies of defects in the surface

layer hardened by the technology of mineral coatings.

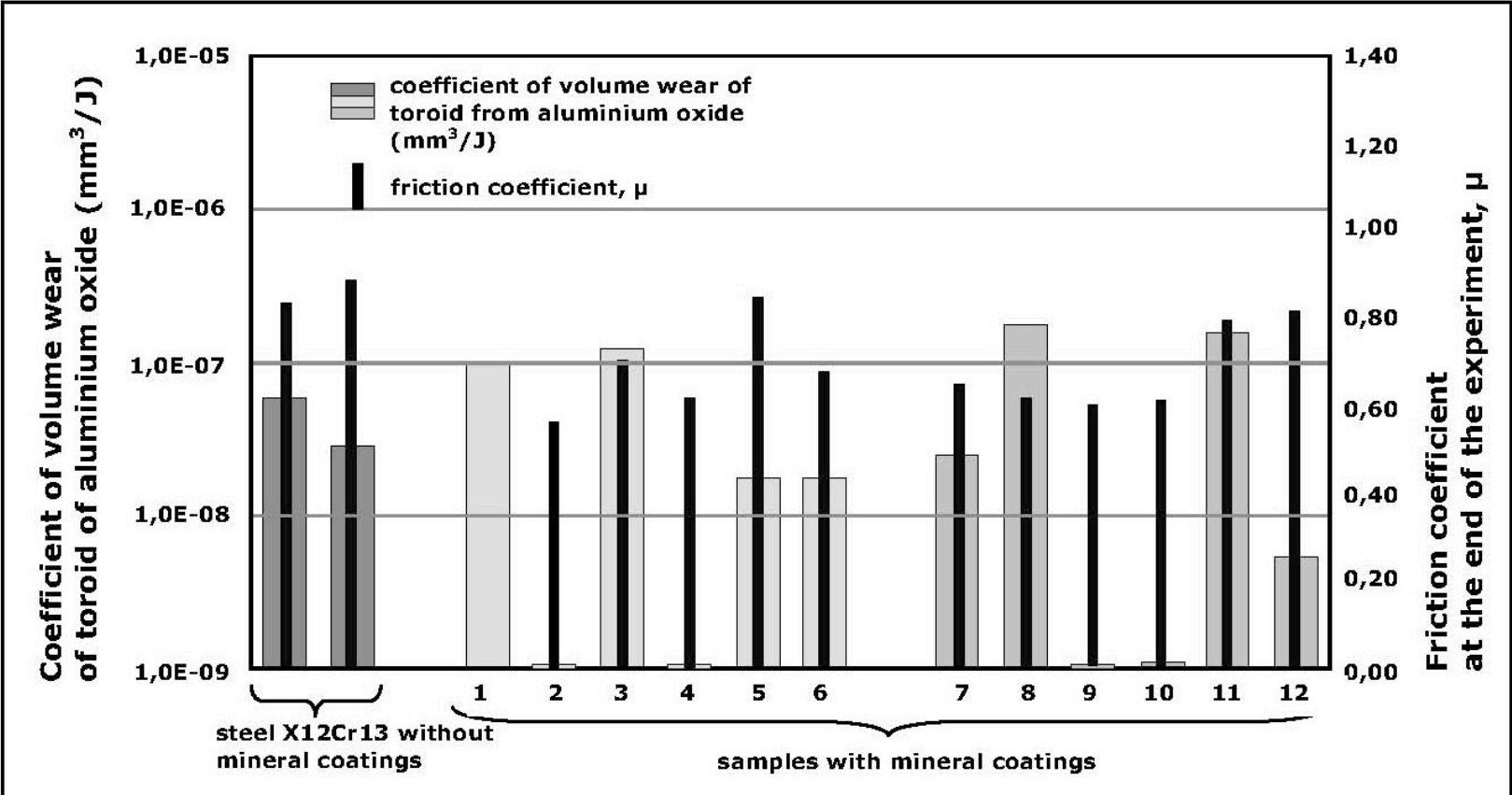

Fig. 5. The volumetric wear coefficients of a toroid made of aluminium oxide with rotating disks made of X12Cr13 steel with mineral coating and without coating in distilled water and sea water.

\section{Conclusion}

The work investigates some tribological parameters of the surfaces of friction pairs made of steel, with mineral layers.

The friction coefficient of samples made of $18 \mathrm{CrNiMo} 7-$ 6 steel with mineral coating and without coating is reduced when the sliding speed is increased, which is typical for a mixed lubrication mode. The lowest friction coefficient value was achieved for samples with mineral coating, without HFC hard surfacing before creating a mineral layer, and it was approximately $15 \%$ lower in comparison with the samples with HFC hard surfacing, but without mineral coating. In our opinion, the probable cause of a decrease in the friction coefficient of samples modified by ultrafine mineral particles is a sharp decrease in the adhesion of surfaces with mineral particles.

The friction coefficient in the temperature range of $30 \ldots 140{ }^{0} \mathrm{C}$, with constant displacement speed of samples with mineral coatings is practically unchanged for every sample type, the variation range does not exceed 0.02 , as contrasted with the friction coefficient of the samples with hard surfacing, but without mineral coating. Traditionally, the stabilization of the friction coefficient is associated with the state of oxide films on the metal surface. It is possible that in the case of the creation of mineral layers, the stable behavior of the friction coefficient with increasing temperature occurs for the same reason. Here, the role of the film is resistant to temperature changes, a layer modified with minerals.

The value of the coefficient of volumetric wear of an aluminum oxide toroid during rotation with disks with some types of mineral coatings was at the level of detection limit (less than $1.2 \times 10^{-9} \mathrm{~mm}^{3} / \mathrm{Nm}$ ), which is significantly less than the coefficient of volume wear of a toroid during rotation with disks without coating (4-7) $\times 10^{-8} \mathrm{~mm}^{3} / \mathrm{Nm}$. To quantify wear, it is necessary to repeat the experiment using certain types of mineral coatings, increasing the total displacement length and the magnitude of the vertical load.

Filling of microcracks with ultradispersed particles and possible changes that occur with defects may have a decisive influence on the development of defects in the surface hardened layer and affect the sharp increase in wear resistance of the material during work of the parts. This assumption requires further studies of defects in the surface layer hardened by the technology of mineral coatings.

In our opinion, practical usefulness and vast potentials of using metal parts with mineral coating in various devices and mechanical assemblies are evident.

This is an Open Access article distributed under the terms of the Creative Commons Attribution License

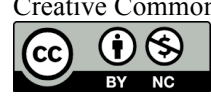

\section{References}

1. V. Panjkovic "Friction and the Hot Rolling of Steel", New York, CRC Press Inc, 2014.

2. B. Bhushan "Modern Tribology Handbook", Two Volume Set, USA, CRC Press Inc, 2000

3. L. Pawlovwski "The Science and Engineering of Thermal Spray Coating", 2-nd Edition, Chichester: John Willey\&Sons, 2008.

4. M. Paczkowska, J. Selech, and A. Piasecki, Surf. Rev. Lett. Vol.23, №03, 1650007, (2016)
5. T. Manokaran, L.Vinoth, V.S. Raja, South Asian Journal of Engineering and Technology Vol.2, №22, 236-244, (2016)

6. E. Richard Booser "Tribology Data Handbook: An Excellent Friction, Lubrication, and Wear Resource", USA, CRC Press Inc, 1997.

7. S.V. Kislov, V.G. Kislov, A.V. Skazochkin, G.G. Bondarenko, A.N. Tikhonov Russian Metallurgy (Metally), Vol. 2015, №7, 558564, (2015). 
Skazochkin Aleksandr V., Bondarenko Gennady G. and Kislov Stanislav V./

Journal of Engineering Science and Technology Review 11 (6) (2018) 138 - 143

8. A.V. Skazochkin, A.S. Useinov, S.V. Kislov Letters on Materials Vol.8, №1, 81-87, (2018).

9. G.V. Darovskoy, I.M. Elmanov, V.N. Polyakov, Journal of Friction and Wear, Vol.36, №5, 368-373 (2015)

10. C. Paulin, D. Chicet, V. Paleu, M. Benchea, Ș. Lupescu, C. Munteanu, IOP Conf. Series: Materials Science and Engineering, 227, (2017)

11. M. Woydt, N. Kelling Industrial Lubrication\&Tribology Vol.55, №5, 213-222, (2003).
12. B. Löffelbein, M. Woydt, K.-H. Habig WEAR Vol.162-164, 220228, (1993).

13. DIN 50905 Corrosion tests, part 1 through 4

14. D.J. Whitehouse "Surfaces and their Measurement", Boston, USA, Butterworth- Heinemann, 2012.

15. S.V. Kislov, , P.V. Balash, V.G. Kislov, A.V. Skazochkin, Valve Industry magazine, №4 (103), 58-63 (2016) 